Mitteilungen der Schweizerischen Gesellschaft fur Phlebologie

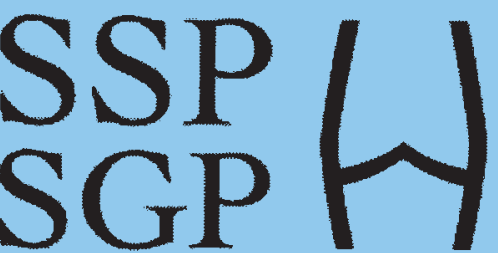

\title{
Report über die Jahrestagung der Schweizerischen Gesellschaft für Phlebologie im Rahmen des European Venous-Forum
}

Zum ersten Mal in der Schweiz und gleich zu seinem 20. Jubiläum hat das European Venous-Forum (EVF) vom 27. bis 29. Juni 2019 in der Universität Zürich stattgefunden. Die Jahrestagung der Schweizerischen Gesellschaft für Phlebologie wurde gleichzeitig durchgeführt. Federführend für die Verbindung zum EVF und die Organisation der ganzen Tagung war PD Dominik Heim, der incoming Präsident des EVF. Trotz der Hitze (Temperaturen um 38 Grad) waren die Konferenzsäle gefüllt und die Sitzungen und Diskussionen hochstehend mit internationalem Publikum. Der Kongress war bereits Wochen im Voraus ausgebucht. Wegen feuerpolizeilichen Auflagen der Universität Zürich musste die Teilnehmerzahl auf 700 limitiert werden.

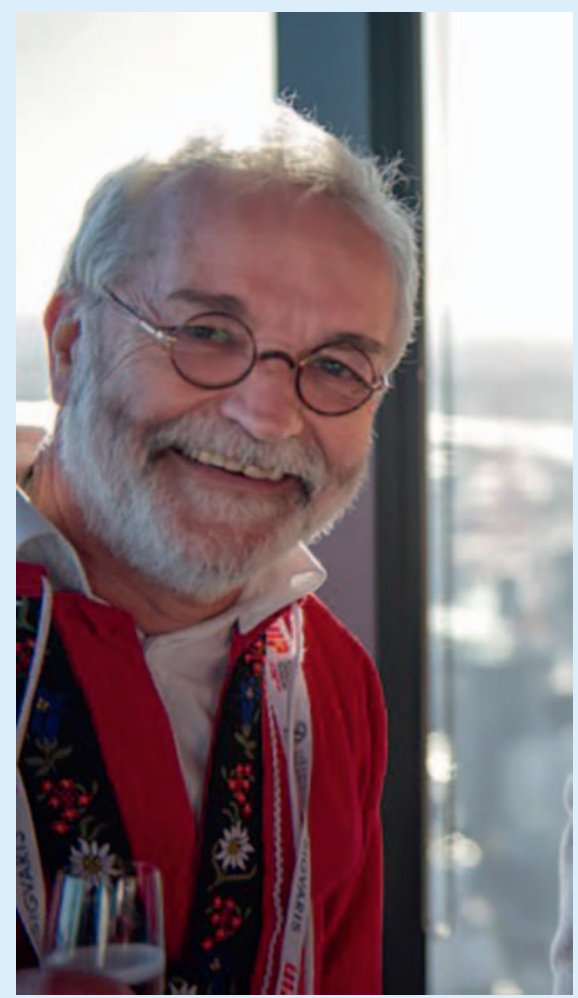

PD Dominik Heim, Präsident des 20. European Venous Forum.
Die Organisatoren entschuldigen sich auch im Nachhinein bei den vor allem schweizeri-

schen Teilnahmewilligen, welche nicht berücksichtigt werden konnten. Zusammenfas-

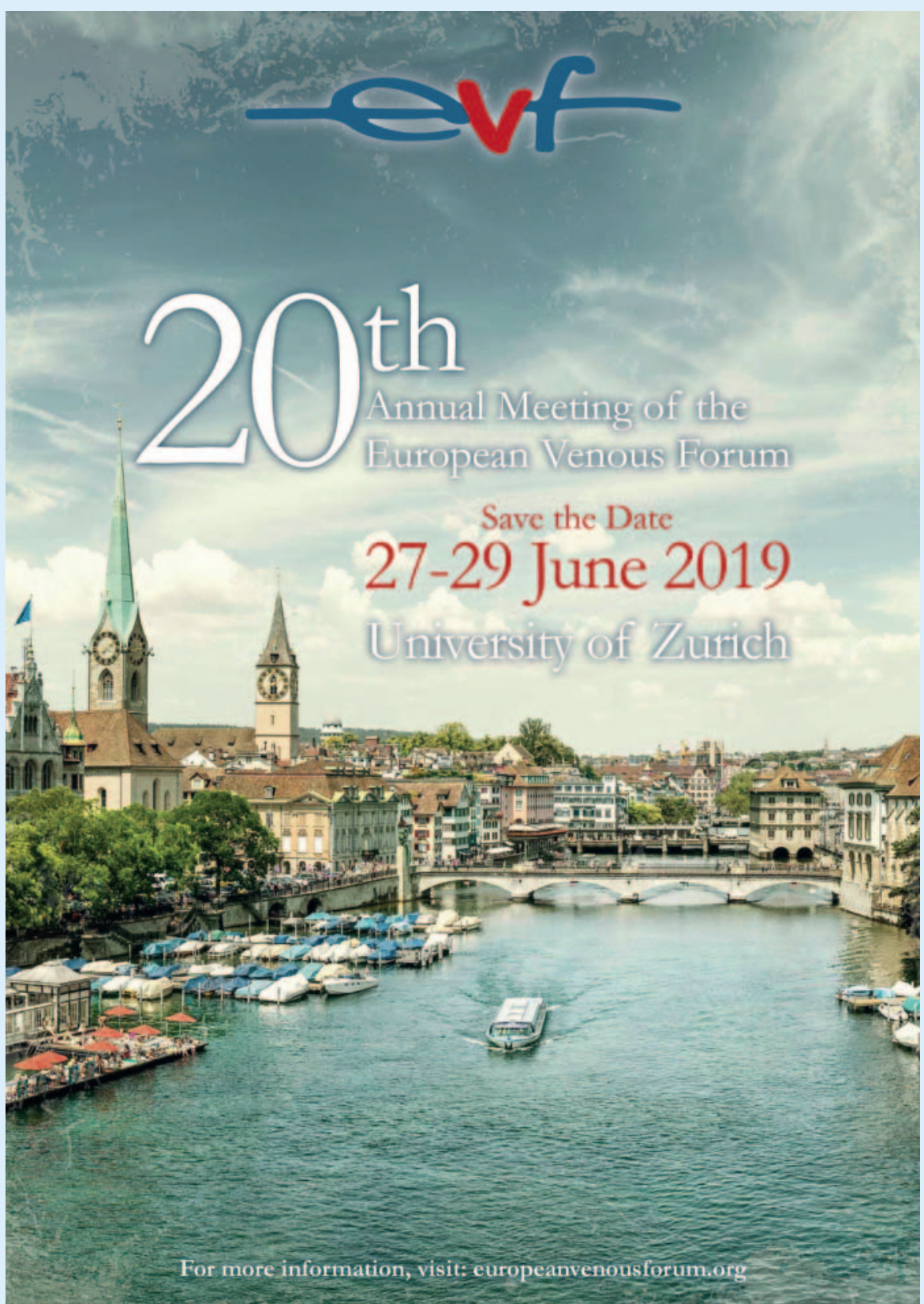

Das 20. European Venous Forum (EVF) hat 2019 erstmalig in Zürich stattgefunden. 


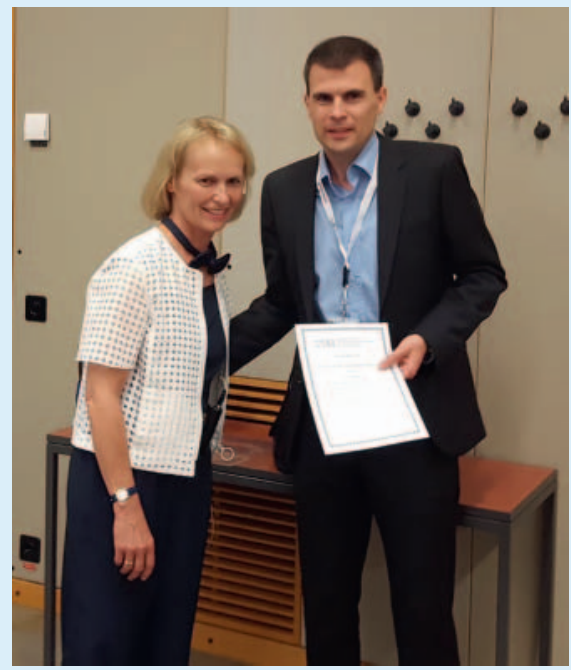

Dr. Luca Spinedi hat den SGP Wissenschaftspreis 2018 für sein Projekt „Endovenous laser ablation of the great saphenous vein up to the common femoral vein: feasibility and safety" erhalten. send wurden die Organisatoren Opfer ihres eigenen Erfolgs. Der Vorstand der SGP dankt PD Dr. Dominik Heim für die großartige wissenschaftliche und logistische Organisation. Für die Verbindung zur Universität Zürich war Prof. Dr. med. Jürg Hafner tätig; auch ihm sei herzlich gedankt für seine Arbeit.

Am Gesellschaftsabend zum 20. Geburtstagsjubiläum der EVF trat Max Lässer mit seiner Band auf, dies als Geburtstagsgeschenk der SGP.

Die SGP ist stolz darauf, dass als erster Schweizer PD Dominik Heim das Präsidium des EVF übernimmt. Christina Jeanneret wurde zum Ehrenmitglied des EVF ernannt.

PD Dominik Heim hat ein tatkräftiges Kongressteam aus ausgezeichnet motivierten
Medizinstudentinnen und Medizinstudenten zusammengestellt, genannt die „Angels“; auch ihnen sei unser großer Dank gewiss.

Auf der Generalversammlung der SGP während der o.g. Tagung wurde das Präsidium der SGP an Prof. Jürg Hafner übergeben. Ebenso fand die Preisverleihung für den SGP-Wissenschaftspreis 2018 statt; er wurde an Dr. Luca Spinedi für das Projekt „Endovenous laser ablation of the great saphenous vein up to the common femoral vein: feasibility and safety“ verliehen.

Wir gratulieren herzlich.

Für die SGP Christina Jeanneret, 18.08.2019, Past Präsidentin SGP 